\title{
Metalaxyl-Resistant Isolates of Phytophthora nicotianae: Occurrence, Sensitivity, and Competitive Parasitic Ability on Citrus
}

\author{
L. W. Timmer and J. H. Graham, Professors, and S. E. Zitko, Senior Biologist, University of Florida, IFAS, Cit- \\ rus Research and Education Center, Lake Alfred 33850
}

\begin{abstract}
Timmer, L. W., Graham, J. H., and Zitko, S. E. 1998. Metalaxyl-resistant isolates of Phytophthora nicotianae: Occurrence, sensitivity, and competitive parasitic ability on citrus. Plant Dis. 82:254-261.

Phytophthora nicotianae was recovered from 8 of 11 nursery sites, and metalaxyl-resistant isolates were detected at 6 of the 8 positive sites. Resistant isolates comprised 31 to $59 \%$ of the population at those sites. Most resistant isolates grew well in the presence of $100 \mu \mathrm{g} / \mathrm{ml}$ of metalaxyl, whereas sensitive isolates did not grow at $1.0 \mu \mathrm{g} / \mathrm{ml}$. Some isolates from mature citrus groves were intermediate in their sensitivity. Metalaxyl-drench treatments failed to control resistant isolates in greenhouse tests, but fosetyl-Al was usually effective. The replacement series technique was used to compare the relative competitive ability of resistant and sensitive isolates in greenhouse tests. Results varied according to the isolate used, but at least some metalaxyl-resistant isolates were able to compete favorably with sensitive isolates in the absence of metalaxyl. In a field test, a high percentage of the population remained resistant to metalaxyl even after 2.5 years without treatment with this fungicide. Excessive use of metalaxyl in nursery situations has reduced the future utility of the product in Florida citrus groves.
\end{abstract}

Phytophthora foot rot and root rot of citrus caused by Phytophthora nicotianae B. de Haan (formerly known as $P$. parasitica Dastur; 13) is a serious problem of citrus in Florida and most other areas of the world $(12,19)$. Use of tolerant rootstocks such as sour orange, trifoliate orange, citranges, and citrumelos provide effective control of bark infection on major roots $(2,11)$. However, many rootstocks that are tolerant to bark infection are susceptible to fibrous root rot, and stocks such as Cleopatra mandarin and rough lemon may be susceptible to both (11). The systemic fungicides metalaxyl and fosetyl-Al have been widely used in citrus to control both diseases. Grove applications of both fungicides in Florida have decreased propagule densities and increased fibrous root densities and citrus yields $(16,21)$.

Phytophthora root rot is also a serious problem in citrus nurseries. A 1987 survey of nurseries in Florida indicated that 8 of 15 field nurseries were infested with $P$. nicotianae, whereas only 1 of 13 of the

Corresponding author: L. W. Timmer

E-mail: 1wt@icon.lal.ufl.edu

This project was supported in part by a grant from Novartis Crop Protection.

Florida Agricultural Experiment Station Journal Series No. R-05931.

Accepted for publication 7 November 1997.

Publication no. D-1997-1219-02R

(C) 1998 The American Phytopathological Society greenhouse operations was infested (24). Fumigation with methyl bromide is sometimes used in Florida citrus nurseries, but post-plant fungicide treatments are more widely applied. After several years of metalaxyl use, many nurseries began to experience control failures. Growers feared that resistant isolates might be carried with nursery trees to groves where metalaxyl would then be ineffective (5).

Metalaxyl resistance is common and widespread in $P$. infestans on potatoes and other crops $(4,10,17)$. Resistant isolates usually tolerate high concentrations, with growth equaling 50 to $100 \%$ of the control at $100 \mu \mathrm{g} / \mathrm{ml}$ metalaxyl. Metalaxyl resistance has been demonstrated to be inherited as a single incompletely dominant gene in several Phytophthora spp. $(3,9,17)$. Resistance appears to be much less common and widespread in Phytophthora spp. which are more strictly soil-borne. Isolates of $P$. erythroseptica from potatoes were classified as sensitive, moderately insensitive, and highly insensitive, with the highly insensitive isolates growing at 85 to $100 \%$ of the control at $100 \mu \mathrm{g} / \mathrm{ml}$ (9). One isolate of $P$. citricola from azalea and two isolates of $P$. parasitica from periwinkle tolerated high levels of metalaxyl (7). Some isolates of $P$. parasitica var. nicotianae from tobacco were considered insensitive but had effective dose $(E D)_{50}$ values of less than $1.0 \mu \mathrm{g} / \mathrm{ml}(6)$.

The purpose of the current investigation was to determine (i) the occurrence of metalaxyl-resistant isolates in Florida citrus; (ii) the sensitivity of the Phytophthora isolates in vitro; (iii) the effectiveness of metalaxyl and fosetyl-Al for control of resistant isolates in the greenhouse; and (iv) the ability of resistant isolates to compete with sensitive isolates in the greenhouse and field.

\section{MATERIALS AND METHODS}

Nursery survey. Soil samples were collected from eight nursery operations representing different citrus-growing areas of Florida from September to November 1992. In some cases, two separate sites (non-adjacent locations in the same general vicinity) owned by the same company were sampled. Nursery managers were questioned to determine their usual programs for control of Phytophthora root rot. All locations sampled were field nursery operations and no greenhouse nurseries were included in the survey. In each case, blocks of trees were chosen which were most likely to have high populations of $P$. nicotianae, i.e., trees were at least 1 year old, were on Cleopatra mandarin or some other susceptible rootstock, were in poorly drained areas, and/or were in a poor state of health.

Sample blocks were about 0.05 to 0.1 ha each, and 2 to 11 blocks were sampled at each site, depending on the size of the nursery. In each block, 15 to 20 core samples, $2.5 \mathrm{~cm}$ in diameter and $30 \mathrm{~cm}$ deep, were collected in areas of high root density and pooled into a single sample. In the laboratory, propagule densities in each sample were determined using the PARPH selective medium (15) and the protocol described in Timmer et al. (20). In addition to the 5 plates of PARPH media used to determine the total propagule density, an additional 5 plates with 10 $\mu \mathrm{g} / \mathrm{ml}$ metalaxyl (as Ridomil 2E) were seeded to determine their sensitivity to metalaxyl.

Sensitivity of isolates. Sixty-eight isolates of $P$. nicotianae were tested to determine their sensitivity to different concentrations of metalaxyl. Forty-two of the isolates evaluated were among those collected in the nursery survey. Four to six isolates were evaluated from each nursery operation where resistance was detected. Most of the isolates tested were from PARPH plates with metalaxyl, but a few isolates from plates without metalaxyl were included. An additional 15 isolates recovered from other nurseries which had experienced failures of control of Phytophthora root rot with metalaxyl were 
tested. The remaining isolates of $P$. nicotianae were from young plantings established with trees from nurseries with problems with metalaxyl resistance or from more mature plantings where the history of metalaxyl use was unknown.

Five-mm diameter plugs of each isolate from 5-day-old cultures grown on clarified V8 juice agar were transferred to duplicate corn meal agar plates containing $0,1,10$, and $100 \mu \mathrm{g} / \mathrm{ml}$ metalaxyl. After the plates were incubated at $27^{\circ} \mathrm{C}$ for 5 days, colony diameters were measured and the areas of the colonies minus the area of the original inoculum plug were calculated. The average colony area was determined for each concentration and expressed as the percentage of the no-fungicide control. For those isolates which grew as well on plates with $100 \mu \mathrm{g} / \mathrm{ml}$ metalaxyl as on control plates, $\mathrm{ED}_{50}$ and $\mathrm{ED}_{90}$ values were designated as greater than $100 \mu \mathrm{g} / \mathrm{ml}$. For isolates which did not grow on plates with 1.0 $\mu \mathrm{g} / \mathrm{ml}$ metalaxyl, $\mathrm{ED}_{50}$ and $\mathrm{ED}_{90}$ values were designated as less than $1.0 \mu \mathrm{g} / \mathrm{ml}$. For other isolates, percentage values were plotted as probits versus the $\log _{10}$ of the fungicide concentration and analyzed by linear regression. The regression equation was used to estimate an $\mathrm{ED}_{50}$ and $\mathrm{ED}_{90}$ value for each isolate.

Greenhouse fungicide evaluations. Three greenhouse experiments were established to evaluate the ability of metalaxyl and fosetyl-Al to control metalaxyl-resistant isolates. Chlamydospores produced by the method of Tsao (22) were used as inoculum. Mycelium and chlamydospores were added to several liters of autoclaved Candler fine sand (typic Quartzipsamments, $\mathrm{pH} 6.8,1 \%$ organic matter) which had been moistened to field capacity, and mixed manually to produce the inoculum concentrate. This inoculum was incubated at room temperature $\left(23\right.$ to $\left.26^{\circ} \mathrm{C}\right)$ for 2 days and then assayed on PARPH media to determine the propagule density. The inoculum concentrate was added to autoclaved Candler fine sand in sufficient quantity to achieve the desired propagule density and thoroughly blended using a cement mixer.
In Experiment 1, metalaxyl treatment was compared to a no-fungicide treatment on plants inoculated with two resistant isolates, Fels 1 and Fels 2, and a non-inoculated control. The resistant isolates were obtained from a young grove near Felsmere in east-central Florida planted with trees from a nursery where metalaxyl resistance had been detected. Both isolates were resistant to metalaxyl at $100 \mu \mathrm{g} / \mathrm{ml}$. Sour orange (Citrus aurantium L.) seedlings were grown in Fafard Citrus Mix B (Conrad Fafard, Inc., Springfield, MA) in plastic tubes about $21 \mathrm{~cm}$ long and $4 \mathrm{~cm}$ in diameter. Three-month-old seedlings about 15 to $20 \mathrm{~cm}$ tall with 8 to 10 leaves each were selected and rinsed free of potting mix. Eight seedlings per treatment were transplanted to black, plastic pots containing 2.3 liters Candler fine sand infested with 8 propagules $/ \mathrm{cm}^{3}$ of the Fels 1 or Fels 2 isolates. Seedlings treated with metalaxyl were drenched with a solution of metalaxyl at $50 \mu \mathrm{g} / \mathrm{ml}\left(2.2 \mu \mathrm{g} / \mathrm{cm}^{3}\right.$ soil $), 100 \mathrm{ml}$ of solution/plant, beginning 10 days prior to transplant to infested soil, while plants were still in the plastic tubes. Additional treatments were made 10 and 30 days after inoculation. Pots were flooded for $48 \mathrm{~h}$ at the time of inoculation and again 2 and 4 weeks later. The experiment was terminated after 6 weeks.

In Experiment 2, treatments with metalaxyl and fosetyl-Al were compared to a no-fungicide control on plants inoculated with the resistant isolate S-BLK-8 (see Experiment 3 below). Nine single-plant replicates of sour orange seedlings were transplanted to soil containing 8 propagules $/ \mathrm{cm}^{3}$ isolate. Fungicides were applied 10 days prior to transplant to infested soil and 10 days after. Soil volumes and inoculum concentrations were as in Experiment 1 . Pots were flooded for $48 \mathrm{~h}$ immediately after inoculation and again 1 and 3 weeks later. The experiment was terminated after 5 weeks.

In Experiment 3, the effect of soil applications of metalaxyl and fosetyl-Al and foliar applications of fosetyl-Al were compared for control of two sensitive isolates, BHG-7 and BLTN, and two resistant isolates, S-BLK-8 and D54S. The resistant isolates, S-BLK-8 and D54S, were recovered from Site 1 and Site 2 of the Avon Park II nursery (Table 1). Both isolates grew well in culture on media containing $100 \mu \mathrm{g} / \mathrm{ml}$ metalaxyl. The sensitive isolates BLTN and BHG-7 were recovered from other nurseries near Tavares and Frostproof, respectively. Neither grew in culture on media containing $1.0 \mu \mathrm{g} / \mathrm{ml}$ metalaxyl. Eight single-plant replicates of sweet orange (C. sinensis (L.) Osb.) seedlings were transplanted to Candler fine sand containing 4 propagules $/ \mathrm{cm}^{3}$ of each isolate in 2.3liter plastic pots. Fosetyl-Al (as Aliette 80 WDG) was applied at $2,400 \mu \mathrm{g} / \mathrm{ml}$ as a drench or foliar spray and metalaxyl was applied at $50 \mu \mathrm{g} / \mathrm{ml}$ as a soil drench using

Table 2. Degree of sensitivity to metalaxyl of isolates of Phytophthora nicotianae from citrus nurseries and groves in Florida

\begin{tabular}{lcrrr}
\hline Source & No. of isolates & $\mathbf{E D}_{\mathbf{5 0}}{ }^{\mathbf{z}}$ & $\mathbf{E D}_{\mathbf{9 0}}$ & Classification \\
\hline Nursery survey & 39 & $>100.0$ & $>100.0$ & Resistant \\
Other nurseries & 3 & $<1.0$ & $<1.0$ & Sensitive \\
\multirow{3}{*}{ Groves } & 10 & $>100.0$ & $>100.0$ & Resistant \\
& 1 & $<1.0$ & $<1.0$ & Sensitive \\
& 6 & $>100.0$ & $>100.0$ & Resistant \\
& 3 & $<1.0$ & $<1.0$ & Sensitive \\
& 1 & $<0.1$ & 0.3 & Insensitive \\
& 1 & $<0.1$ & 4.6 & Insensitive \\
& 1 & 0.1 & 10.0 & Insensitive \\
& 1 & 0.26 & 4.1 & Insensitive \\
& 1 & 0.21 & 2.3 & Insensitive \\
& 1 & 0.36 & 8.1 & Insensitive \\
\hline
\end{tabular}

${ }^{\mathrm{z}} \mathrm{ED}=$ effective dose

Table 1. Survey of Florida citrus nurseries to determine the prevalence of metalaxyl-resistant isolates of Phytophthora nicotianae

\begin{tabular}{|c|c|c|c|c|c|c|}
\hline \multirow[b]{2}{*}{ Nursery operations } & \multirow[b]{2}{*}{ Site } & \multirow[b]{2}{*}{ Phytophthora control program } & \multirow[b]{2}{*}{ No. of blocks sampled } & \multicolumn{2}{|c|}{ Propagules $/ \mathrm{cm}^{3}$} & \multirow[b]{2}{*}{ Metalaxyl-resistant $(\%)^{z}$} \\
\hline & & & & Avg. & Range & \\
\hline Immokalee & & B & 7 & 52 & $0-128$ & 55 \\
\hline \multirow{2}{*}{ La Belle I } & 1 & A & 6 & 90 & $0-152$ & 58 \\
\hline & 2 & $\mathrm{~A}$ & 2 & 0 & & $\ldots$ \\
\hline \multirow[t]{2}{*}{ La Belle II } & 1 & A & 5 & 58 & $0-126$ & 51 \\
\hline & 2 & A & 6 & 0 & & \\
\hline Lorida & & $\mathrm{D}$ & 8 & 9 & $0-66$ & 0 \\
\hline Lake Placid & & $\mathrm{D}$ & 8 & 10 & $0-26$ & 0 \\
\hline Sebring & & $\mathrm{C}$ & 5 & 0 & $\ldots$ & $\ldots$ \\
\hline Avon Park I & & A & 8 & 48 & $0-104$ & 35 \\
\hline \multirow[t]{2}{*}{ Avon Park II } & 1 & $\mathrm{~B}$ & 11 & 20 & $0-58$ & 31 \\
\hline & 2 & B & 7 & 18 & 0.70 & 54 \\
\hline
\end{tabular}

y A = metalaxyl used exclusively; B = metalaxyl and fosetyl-Al alternated; $\mathrm{C}=$ fumigation only; $\mathrm{D}=$ fumigation and metalaxyl and fosetyl-Al alternated.

${ }^{\mathrm{z}}$ Percentage of isolates able to grow on media containing $1.0 \mu \mathrm{g} / \mathrm{ml}$ of metalaxyl. 
$100 \mathrm{ml} /$ plant. Fungicide applications were made 10 days before transplant to infested soil and at 10 days and 4 weeks afterward. Pots were flooded for $48 \mathrm{~h}$ at the time of inoculation and again 2 and 4 weeks later. The experiment was terminated 5 weeks after inoculation.

At the end of each experiment, the percent root rot, the percentages of root pieces infected, and the propagule density in the soil were determined for each plant. Seedlings were gently removed from the soil and the roots rinsed free of soil particles. The percentage of root rot was determined by visually examining up to 100 root tips per plant, if available, on each seedling and determining the percentage of rotted tips. One hundred root pieces selected at random from each plant, each about $1 \mathrm{~cm}$ long, were plated directly on PARPH medium. Plates were incubated for 3 days at $27^{\circ} \mathrm{C}$ and the percentage of roots infected by $P$. nicotianae determined. The soil from each pot was mixed thoroughly and a 10- $\mathrm{cm}^{3}$ sample was removed from each pot. Propagule densities were determined as described above.

Competitive ability of metalaxyl-resistant isolates. Greenhouse studies. The ability of metalaxyl-resistant isolates to compete with sensitive isolates was evaluated in three replacement series experiments $(1,23)$ in the greenhouse. Resistant isolates S-BLK-8 and D54S and sensitive isolates BLTN and BHG-7 were compared in the following pairings: S-BLK-8 vs.

Table 3. Effect of metalaxyl and fosetyl-Al on root rot of sour orange seedlings caused by metalaxyl-resistant isolates of Phytophthora nicotianae in 2 greenhouse tests

\begin{tabular}{|c|c|c|c|c|}
\hline Fungicide treatment & Isolate & Root $\operatorname{rot}(\%)$ & Root pieces infected (\%) & Propagules $/ \mathrm{cm}^{3}$ \\
\hline \multicolumn{5}{|l|}{ Experiment 1} \\
\hline Metalaxyl - $50 \mu \mathrm{g} / \mathrm{ml}$ & Fels 1 & 55 & 42 & 24 \\
\hline No fungicide & Fels 1 & 51 & 32 & 10 \\
\hline Metalaxyl - $50 \mu \mathrm{g} / \mathrm{ml}$ & Fels 2 & 28 & 28 & $15^{\mathrm{y}}$ \\
\hline No fungicide & Fels 2 & 44 & 25 & 47 \\
\hline Metalaxyl - $50 \mu \mathrm{g} / \mathrm{ml}$ & Not inoculated & 3 & 0 & 0 \\
\hline No fungicide & Not inoculated & 4 & 0 & 0 \\
\hline \multicolumn{5}{|l|}{ Experiment 2} \\
\hline Metalaxyl - $50 \mu \mathrm{g} / \mathrm{ml}$ & S-BLK-8 & $27 \mathrm{~b}^{\mathrm{z}}$ & $11 \mathrm{a}$ & $24 \mathrm{a}$ \\
\hline Fosetyl-Al - $100 \mu \mathrm{g} / \mathrm{ml}$ & S-BLK-8 & $31 \mathrm{ab}$ & $2 \mathrm{~b}$ & $1 \mathrm{~b}$ \\
\hline No fungicide & Not inoculated & $37 \mathrm{a}$ & $15 \mathrm{a}$ & $15 \mathrm{a}$ \\
\hline
\end{tabular}

y Mean significantly different from the no-fungicide control according to Student's $t$ test, $P \leq 0.05$. All other means were not significantly different from the corresponding control.

${ }^{\mathrm{z}}$ Mean separation by the Waller-Duncan $k$-ratio $t$ test, $P \leq 0.05$.

Table 4. Effect of metalaxyl and fosetyl-Al on Phytophthora root rot of sweet orange seedlings caused by metalaxyl-resistant and sensitive isolates of Phytophthora nicotianae (Experiment 3)

\begin{tabular}{|c|c|c|c|c|}
\hline Fungicide treatment & Isolate & Root $\operatorname{rot}(\%)$ & Root pieces infected (\%) & Propagules $/ \mathrm{cm}^{3}$ \\
\hline Metalaxyl; drench & BHG-7 $(\mathrm{S})^{\mathrm{y}}$ & $13 b^{z}$ & $0 \mathrm{~b}$ & $0 \mathrm{~b}$ \\
\hline Fosetyl-Al; drench & BHG-7 & $30 \mathrm{a}$ & $0 \mathrm{~b}$ & $0 \mathrm{~b}$ \\
\hline Fosetyl-Al; foliar & BHG-7 & $13 \mathrm{~b}$ & $0 \mathrm{~b}$ & $0 \mathrm{~b}$ \\
\hline Control & BHG-7 & $27 \mathrm{a}$ & $20 \mathrm{a}$ & $80 \mathrm{a}$ \\
\hline Metalaxyl; drench & BLTN (S) & $16 \mathrm{~b}$ & $1 \mathrm{~b}$ & $0 \mathrm{~b}$ \\
\hline Fosetyl-Al; drench & BLTN & $18 \mathrm{ab}$ & $1 \mathrm{~b}$ & $0 \mathrm{~b}$ \\
\hline Fosetyl-Al; foliar & BLTN & $11 \mathrm{~b}$ & $1 \mathrm{~b}$ & $0 \mathrm{~b}$ \\
\hline Control & BLTN & $30 \mathrm{a}$ & $6 \mathrm{a}$ & $49 \mathrm{a}$ \\
\hline Metalaxyl; drench & S-BLK-8 (R) & $35 \mathrm{a}$ & $40 \mathrm{a}$ & $114 \mathrm{a}$ \\
\hline Fosetyl-Al; drench & S-BLK-8 & $37 \mathrm{a}$ & $0 \mathrm{~b}$ & $0 \mathrm{~b}$ \\
\hline Fosetyl-Al; foliar & S-BLK-8 & $7 \mathrm{~b}$ & $0 \mathrm{~b}$ & $0 \mathrm{~b}$ \\
\hline Control & S-BLK-8 & $33 \mathrm{a}$ & $48 \mathrm{a}$ & $148 \mathrm{a}$ \\
\hline Metalaxyl; drench & D54S (R) & $25 \mathrm{a}$ & $9 \mathrm{ab}$ & $11 \mathrm{~b}$ \\
\hline Fosetyl-Al; drench & D54S & $28 \mathrm{a}$ & $0 \mathrm{~b}$ & $0 \mathrm{~b}$ \\
\hline Fosetyl-Al; foliar & D54S & $13 \mathrm{~b}$ & $0 \mathrm{~b}$ & $0 \mathrm{~b}$ \\
\hline Control & D54S & $17 \mathrm{~b}$ & $20 \mathrm{a}$ & $34 \mathrm{a}$ \\
\hline
\end{tabular}

y $\mathrm{S}=$ sensitive; $\mathrm{R}=$ resistant.

${ }^{\mathrm{z}}$ Mean separation within columns and within isolates by the Waller-Duncan $k$-ratio $t$ test, $P \leq 0.05$.

Table 5. The effect of different proportions of metalaxyl-resistant and -sensitive isolates on the percentage root rot and root weights of sour orange seedlings treated or not treated with metalaxyl

\begin{tabular}{|c|c|c|c|c|c|c|c|c|c|c|c|c|}
\hline \multirow{3}{*}{$\begin{array}{l}\text { Inoculum } \\
\text { proportion (R:S) }\end{array}$} & \multicolumn{4}{|c|}{ S-BLK-8 (R) vs. BLTN $(\text { S })^{x}$} & \multicolumn{4}{|c|}{ D54S (R) vs. BLTN (S) } & \multicolumn{4}{|c|}{ S-BLK-8 (R) vs. BHG-7 (S) } \\
\hline & \multicolumn{2}{|c|}{ Root rot $(\%)$} & \multicolumn{2}{|c|}{ Root wt (g) } & \multicolumn{2}{|c|}{ Root $\operatorname{rot}(\%)$} & \multicolumn{2}{|c|}{ Root wt (g) } & \multicolumn{2}{|c|}{ Root $\operatorname{rot}(\%)$} & \multicolumn{2}{|c|}{ Root wt (g) } \\
\hline & met $(-)^{y}$ & met $(+)$ & met (-) & met $(+)$ & met (-) & met $(+)$ & met (-) & met $(+)$ & met (-) & met $(+)$ & met (-) & met $(+)$ \\
\hline 4:0 & $29 b^{z}$ & $39 a$ & 0.83 & $0.86 b$ & 57 & $40 \mathrm{a}$ & $0.21 b$ & $0.34 \mathrm{~b}$ & $27 \mathrm{a}$ & $26 \mathrm{a}$ & $0.18 b$ & $0.16 b c$ \\
\hline $3: 1$ & $39 \mathrm{ab}$ & $22 \mathrm{~b}$ & 0.75 & $0.96 \mathrm{ab}$ & $48 \mathrm{ab}$ & $50 \mathrm{a}$ & $0.23 \mathrm{~b}$ & $0.31 \mathrm{~b}$ & $27 \mathrm{a}$ & $23 \mathrm{a}$ & $0.12 \mathrm{~b}$ & $0.14 \mathrm{c}$ \\
\hline $2: 2$ & $35 \mathrm{ab}$ & $23 \mathrm{~b}$ & 0.73 & $0.75 \mathrm{~b}$ & $43 \mathrm{bc}$ & $46 \mathrm{a}$ & $0.39 \mathrm{~b}$ & $0.35 \mathrm{~b}$ & $27 \mathrm{a}$ & $22 \mathrm{ab}$ & $0.15 \mathrm{~b}$ & $0.17 b c$ \\
\hline $1: 3$ & $30 \mathrm{~b}$ & $15 \mathrm{bc}$ & 0.69 & $1.49 \mathrm{ab}$ & $31 \mathrm{~cd}$ & $39 a$ & $0.35 \mathrm{~b}$ & $0.31 \mathrm{~b}$ & $25 \mathrm{a}$ & $18 \mathrm{~b}$ & $0.15 \mathrm{~b}$ & $0.20 \mathrm{~b}$ \\
\hline $0: 4$ & $46 a$ & $10 \mathrm{c}$ & 0.94 & $1.72 \mathrm{a}$ & $27 \mathrm{~d}$ & $4 \mathrm{~b}$ & $0.71 \mathrm{a}$ & $0.67 \mathrm{a}$ & $21 \mathrm{a}$ & $18 \mathrm{~b}$ & $0.15 \mathrm{~b}$ & $0.18 b c$ \\
\hline 0:0 & $4 \mathrm{c}$ & $5 \mathrm{c}$ & $\begin{array}{l}0.86 \\
\text { N.S. }\end{array}$ & $1.32 \mathrm{ab}$ & $2 \mathrm{e}$ & $2 \mathrm{~b}$ & $0.93 \mathrm{a}$ & $0.78 \mathrm{a}$ & $3 b$ & $3 \mathrm{c}$ & $0.35 \mathrm{a}$ & $0.31 \mathrm{a}$ \\
\hline
\end{tabular}

${ }^{\mathrm{x}} \mathrm{R}=$ resistant, $\mathrm{S}=$ sensitive.

y met $(-)=$ not treated with metalaxyl; met $(+)=$ treated with metalaxyl at $50 \mu \mathrm{g} / \mathrm{ml}$.

${ }^{\mathrm{z}}$ Mean separation within columns by the Waller-Duncan $k$-ratio $t$ test, $P \leq 0.05$; N.S. $=$ not significant. 
BLTN, D54S vs. BLTN, and S-BLK-8 vs. BHG-7. Inoculum preparation of each isolate was as described for the fungicide experiments. Mixtures of resistant and sensitive isolates were prepared in the following proportions: 4:0, 3:1, 2:2, 1:3, and $0: 4$, with final combined inoculum densities of 8 propagules $/ \mathrm{cm}^{3}$ in Candler fine sand.

Sour orange seedlings were grown and selected as for the fungicide experiments. Seven single-tree replicates were used for the S-BLK-8 vs. BLTN pairing and eight replications were used for the other pairings. A non-inoculated control was included in each experiment. One complete set of treatments received no fungicide, and in another set, metalaxyl at $50 \mu \mathrm{g} / \mathrm{ml}$ was applied as a drench at 10 days prior to transplant and again 10 and 30 days afterward. Plants were flooded for $48 \mathrm{~h}$ immediately after transplant and again at 2 and 4 weeks later. The experiments were terminated after 5 weeks.

At the end of the experiments, the percentage root rot, the percentage of infected roots, and the propagule densities were determined as in the fungicide experiments. Root and soil samples from each plant were plated on sets of PARPH plates with and without metalaxyl at $10 \mu \mathrm{g} / \mathrm{ml}$. Root weight of each plant was determined by removing all of the fibrous roots, drying them at $65^{\circ} \mathrm{C}$ to a constant weight, and weighing.

For replacement series experiments, the yield of each species in single culture, i.e., the percentage of root infection or the propagule density, is taken as unity and the yield of each species in mixed inoculations is expressed as the proportion of that recovered in single culture $(1,23)$. If interand intra-isolate competition is equal, then isolate recovery should be in the same proportion as that used in the inoculum. Data on percentages of root infection and on propagule densities in these experiments were expressed graphically in this manner and compared to the theoretical relative yields of each isolate. The pairwise $t$ test was used to compare observed relative yields with theoretical yields. In addition, the lack-of-fit regression test (PROC RSREG procedure, SAS Institute, Cary, NC) was used to determine whether observed responses were significantly different from the expected linear response (1). The relative total yield, the sum of the relative yield of resistant isolates plus the relative yield of sensitive isolates, was compared to the theoretical relative yield of one using a non-parametric sign test. The observed relative total yield values for the $3: 1,2: 2$, and $1: 3$ inoculum ratios were categorized as greater or less than the theoretical (1.0) and the probability that the distribution was due to chance was determined (18). Other factors, such as root rot severity and root weights, were subjected to analysis of variance, and means sepa- rated using the Waller-Duncan $k$-ratio $t$ test.

Field study. In 1994, a study of the ability of metalaxyl-resistant isolates to persist in the field was initiated in a 2-year-old grove of Sunburst tangerine $(C$. reticulata Blanco) on Cleopatra mandarin (C. reshni Hort ex. Tan) rootstock near Felsmere, Florida. The grove had been planted with trees from a nursery in which metalaxylresistant isolates had been detected. The grove was planted on beds with furrows between each bed. The planting was not tilled, weeds were controlled by herbicides, and irrigation was applied by microsprinkler, thus minimizing the opportunity for movement of soil between trees. Initially, about 70 individual trees in the grove were sampled and the number of propagule $/ \mathrm{cm}^{3}$ soil of metalaxyl-resistant and sensitive $P$. nicotianae was determined as described above. Trees were divided into three categories: high resistance $=80$ to $100 \%$ of the population resistant, low resistance $=$ less than $20 \%$ of the population resistant; and zero $=$ all isolates sensitive to metalaxyl. Five to seven trees in each category were then arbitrarily designated to receive metalaxyl treatment and an equal number to remain untreated.

Three times each year, all trees were sampled to determined the propagule densities of resistant and sensitive isolates using a composite sample of four $2.5-\mathrm{cm}$

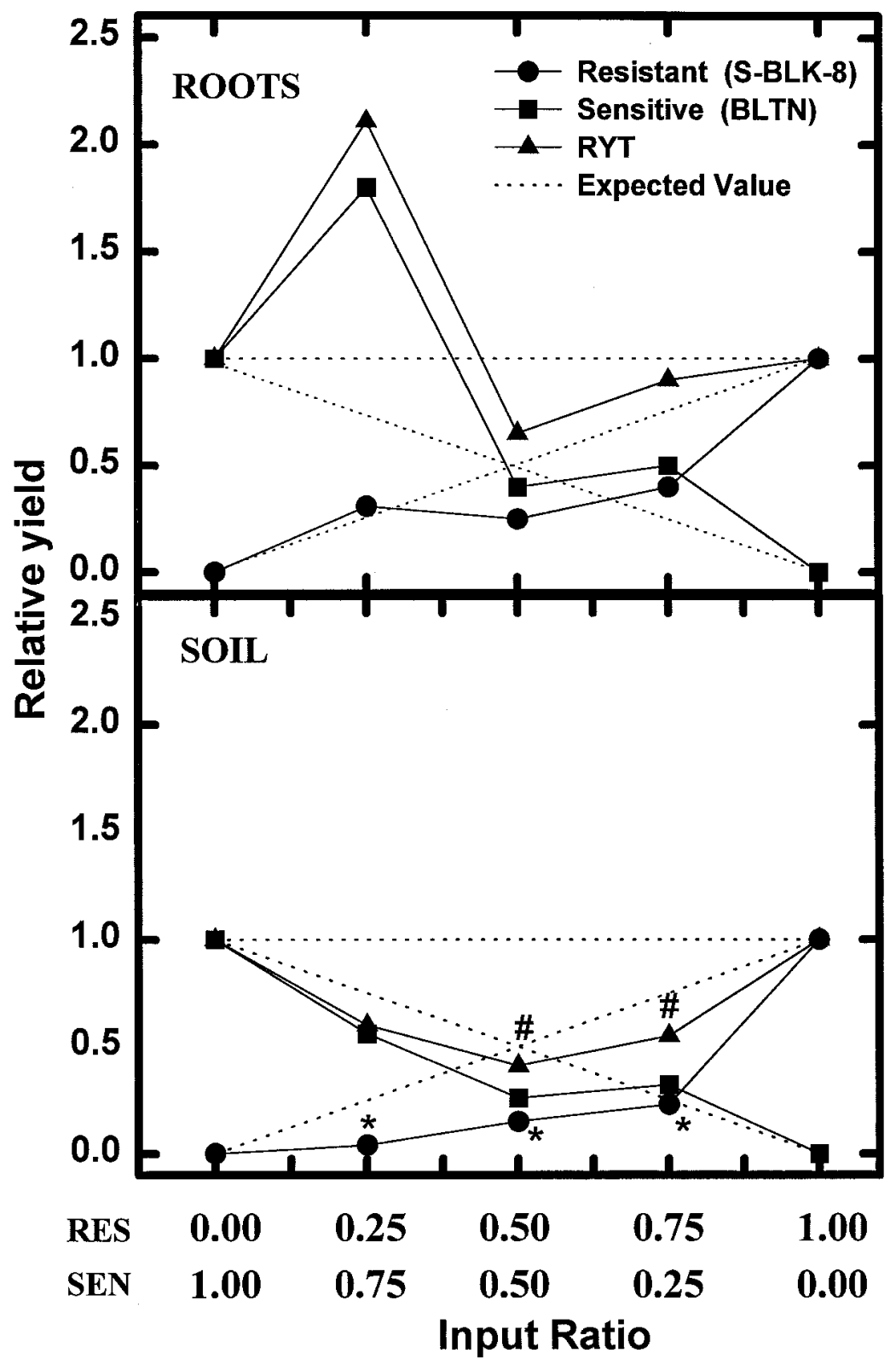

Fig. 1. Relative recoveries of a metalaxyl-resistant isolate (S-BLK-8) and a sensitive isolate (BLTN) from sour orange roots and from soil 5 weeks after inoculation with different inoculum density ratios. RYT = relative total yield of both isolates. Expected values (dotted lines) are the reference values indicating equal inter- and intra-isolate competition. $*=$ significantly different from the reference values for each species according to the $t$ test, $P \leq 0.05$. \# = Value of RYT significantly different from the reference value (1.0) according to a non-parametric sign test. 
diameter by $30-\mathrm{cm}$ deep cores beneath the drip line of each tree. Propagule densities were determined as described above. Metalaxyl as Ridomil 2E was applied to the soil surface around the designated trees with a pressurized hand sprayer, using 8.7 $\mathrm{ml}$ product in 7.0 liters water, immediately after each sample collection time. After treatments were completed, the microsprinkler irrigation system was used to apply 10 to $15 \mathrm{~mm}$ water to move the product into the soil.

\section{RESULTS}

Nursery survey. $P$. nicotianae was present in 7 of 8 nursery operations, but not necessarily at all sites within an operation. Metalaxyl-resistant isolates were recovered from 5 of 8 operations (Table 1). Where metalaxyl resistance was found, populations were generally high and a high percentage $(>30 \%)$ of the isolates was resistant.

Metalaxyl resistance occurred commonly where nurserymen used only this product, but also occurred where applications of fosetyl-Al were alternated with metalaxyl. Metalaxyl-resistant isolates were absent whenever methyl bromide was part of the program.

Sensitivity of isolates. All of the nursery isolates of $P$. nicotianae, which were recovered from plates amended with 10 $\mu \mathrm{g} / \mathrm{ml}$ of metalaxyl, tolerated high levels of

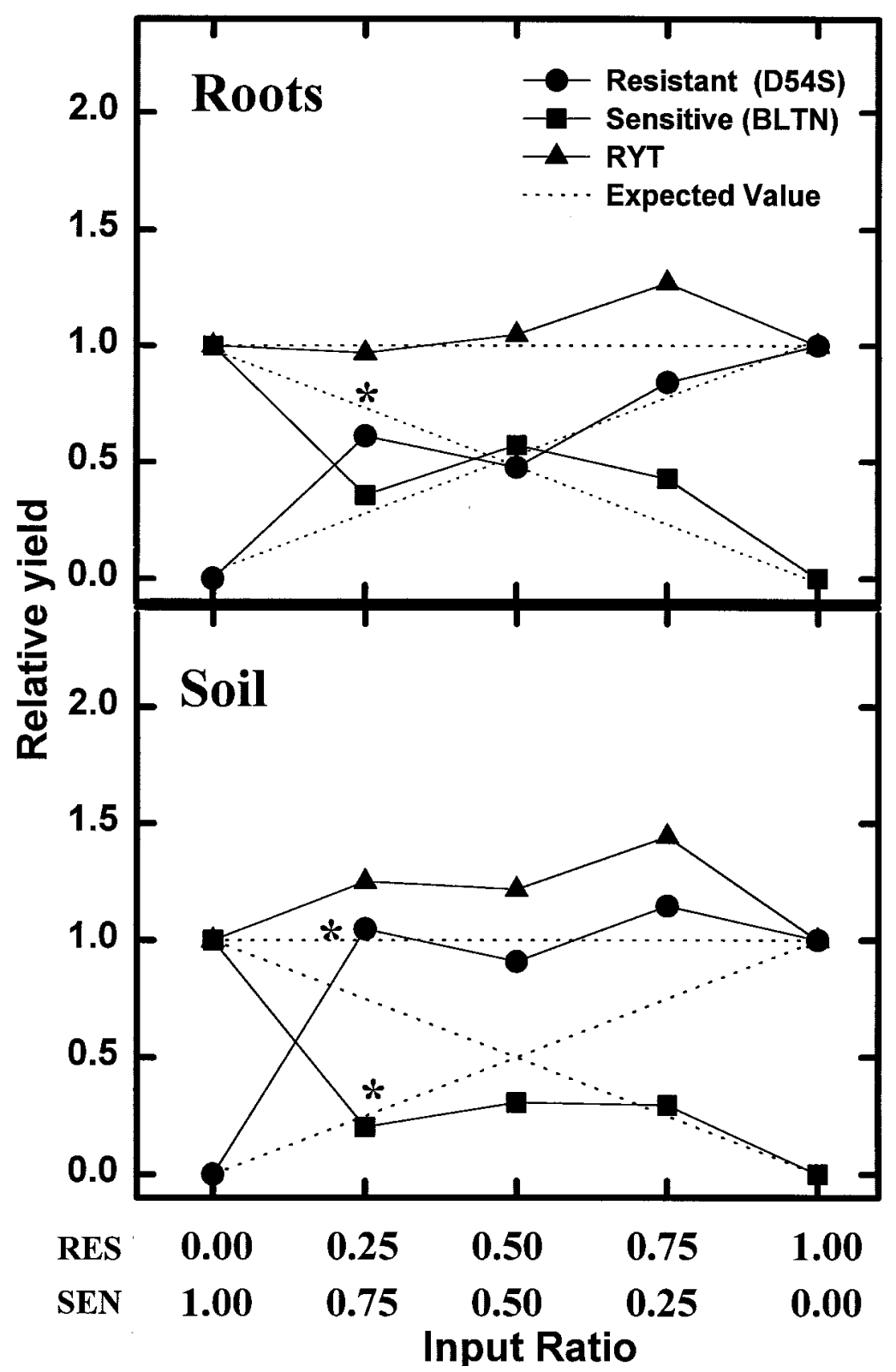

Fig. 2. Relative recoveries of a metalaxyl-resistant isolate (D54S) and a sensitive isolate (BLTN) from sour orange roots and from soil 5 weeks after inoculation with different inoculum density ratios. $\mathrm{RYT}=$ relative total yield of both isolates. Expected values (dotted lines) are the reference values indicating equal inter- and intra-isolate competition. ${ }^{*}=$ significantly different from the reference values for each species according to the $t$ test, $P \leq 0.05$. Values of RYT were not significantly different from the reference value (1.0) according to a non-parametric sign test. the fungicide. Resistant isolates grew as well or faster on plates with metalaxyl than on fungicide-free media. All of the nursery isolates which were resistant had $\mathrm{ED}_{50}$ values greater than $100 \mu \mathrm{g} / \mathrm{ml}$, whereas the sensitive isolates produced virtually no growth on media with $1.0 \mu \mathrm{g} / \mathrm{ml}$ (Table 2). All of the resistant isolates from grove soils were recovered from locations which had been planted with trees from nurseries which had a history of problems with metalaxyl resistance. A number of isolates from groves were intermediate in their tolerance to metalaxyl and were termed insensitive (Table 2).

Greenhouse evaluations. In Experiment 1 , metalaxyl failed to reduce root rot or the percentage of root pieces infected on seedlings inoculated with two metalaxylresistant isolates (Table 3). With the Fels 2, but not the Fels 1 isolate, metalaxyl reduced the propagule density compared to the non-treated control.

In Experiment 2, metalaxyl reduced the percentage of roots rotted slightly, but did not reduce the percentage of roots infected or propagule densities (Table 3). FosetylAl failed to control root rot, but reduced the percentage of the roots infected and the propagule densities.

In Experiment 3, metalaxyl and the foliar application treatment with fosetyl-Al reduced root rot, root infection, and propagule densities of the two metalaxyl-sensitive isolates (Table 4). With the resistant isolates, metalaxyl did not control root rot or root infection, but reduced propagule densities with one isolate. The foliar application of fosetyl-Al was effective against resistant isolates. Drench application of fosetyl-Al did not control root rot caused by any isolate. This product was very effective in reducing infection and propagule densities, but may have been phytotoxic at the rate used.

Competitive ability of metalaxyl-resistant isolates. Greenhouse studies. In the first competitive experiment, S-BLK-8 vs. BLTN, the recovery of resistant and sensitive strains from roots was as expected from the proportions introduced (Fig. 1) However, propagule densities of the resistant isolate in soil were lower than expected from the proportions introduced. The depression of relative total yield indicated that while the densities of the resistant isolate were depressed, the sensitive isolate did not increase in response. The plants which were not treated with metalaxyl developed only small differences in root rot percentage in response to the different proportions of inoculum of the two isolates, and no difference in root weights (Table 5). In the series of plants treated with metalaxyl, the percentage of root rot decreased and root weights increased as the proportion of the sensitive isolate in the inoculum increased.

In the D54S vs. BLTN pairing, the resistant isolate was recovered from roots at 
a slightly higher frequency than expected in one case (Fig. 2). Propagules densities in soil of the resistant isolates were generally higher than expected and sensitive isolates were lower. The relative total yield was not significantly different from unity in either case, indicating that intra-isolate competition was equal to or greater than inter-isolate competition. In the absence of metalaxyl, D54S (R) caused more root rot and reduced root weight more than BLTN (S) (Table 5). Thus, the resistant isolate was more aggressive than the sensitive one. Metalaxyl treatment had no effect on root rot percentage or root weight as long as any proportion of the resistant isolate was present in the inoculum.

With the S-BLK-8 vs. BHG-7 combination, the recovery of both isolates from roots or soil did not differ greatly from that expected, and relative total yield values did not differ significantly from unity (Fig. 3). In one case on roots, recovery of the sensitive isolate was higher than expected. In the series without metalaxyl treatment, the percentage of root rot and root weights were not significantly different among inoculum proportions, indicating that the isolates were comparable in aggressiveness (Table 5). Metalaxyl treatment reduced root rot and increased root weight only where the proportion of the sensitive isolate was high.

Field study. Total propagule densities of resistant and sensitive isolates were high throughout the study period, and analysis of variance indicated that sample date had no significant effect on propagule density when evaluated across metalaxyl- and nottreated trees $(P=0.12$; Table 6$)$. Total propagule densities across metalaxyl- and not-treated trees were significantly higher in the trees selected for high and low resistance than on those with no resistance $(P$ $=0.01)$, with an average propagules $/ \mathrm{cm}^{3}$ soil of 28 on those with high resistance, 30 on trees with low resistance, and 17 on trees with no resistant isolates. Despite the widespread occurrence of resistant isolates, metalaxyl significantly reduced propagule densities from 30 in the non-treated trees to 19 propagules $/ \mathrm{cm}^{3}$ soil in the treated plots across high-, low-, and no-resistance plots. A $t$ test indicated that there was a significant reduction even for the trees with high levels of resistance. However, regression analysis indicated that there was a small but significant increase in propagule densities over time in the metalaxyl-treated trees with high, low, and no resistance (Table 6). No such trend was observed in trees not treated with metalaxyl at any level of resistance. There was no indication of a change in the percentage of resistant isolates over time in any treatment. Over all sample dates and categories of trees, metalaxyl treatment had no significant effect on the percentage of resistant isolates $(P=0.86)$.

\section{DISCUSSION}

In our survey of citrus nurseries in Florida, we found that 8 of 11 sites had $P$. nicotianae present in at least some nursery beds. Of the 8 sites with $P$. nicotianae present, 5 had metalaxyl-resistant isolates which constituted 31 to $59 \%$ of the populations. A subsequent, more extensive survey conducted by Ciba-Geigy Corp. (now Novartis Crop Protection) found that $P$. nicotianae was present in 39 of 41 field nurseries in Florida, and that 25 of the 39 had metalaxyl-insensitive isolates (8). In greenhouse, container-grown nursery operations, 17 of 22 nurseries had $P$. nicotianae present and 10 of the 17 had metalaxyl-insensitive isolates present. In the 1987 survey of citrus nurseries, $P$. nicotianae was found in about half of the field nurseries and only rarely in greenhouse operations (24). The more recent surveys indicate that $P$. nicotianae is much more widespread, especially in greenhouse operations, and that metalaxyl resistance is very common throughout. Only a few field nurseries were sampled in our survey, but it appeared that those using fumigation were more successful in limiting the development of metalaxyl resistance. Alternation of fosetyl-Al with metalaxyl did not appear to reduce occurrence of resistance to metalaxyl. The abandonment of fumigation and sanitation practices in citrus nurseries in favor of the use of systemic fungi-

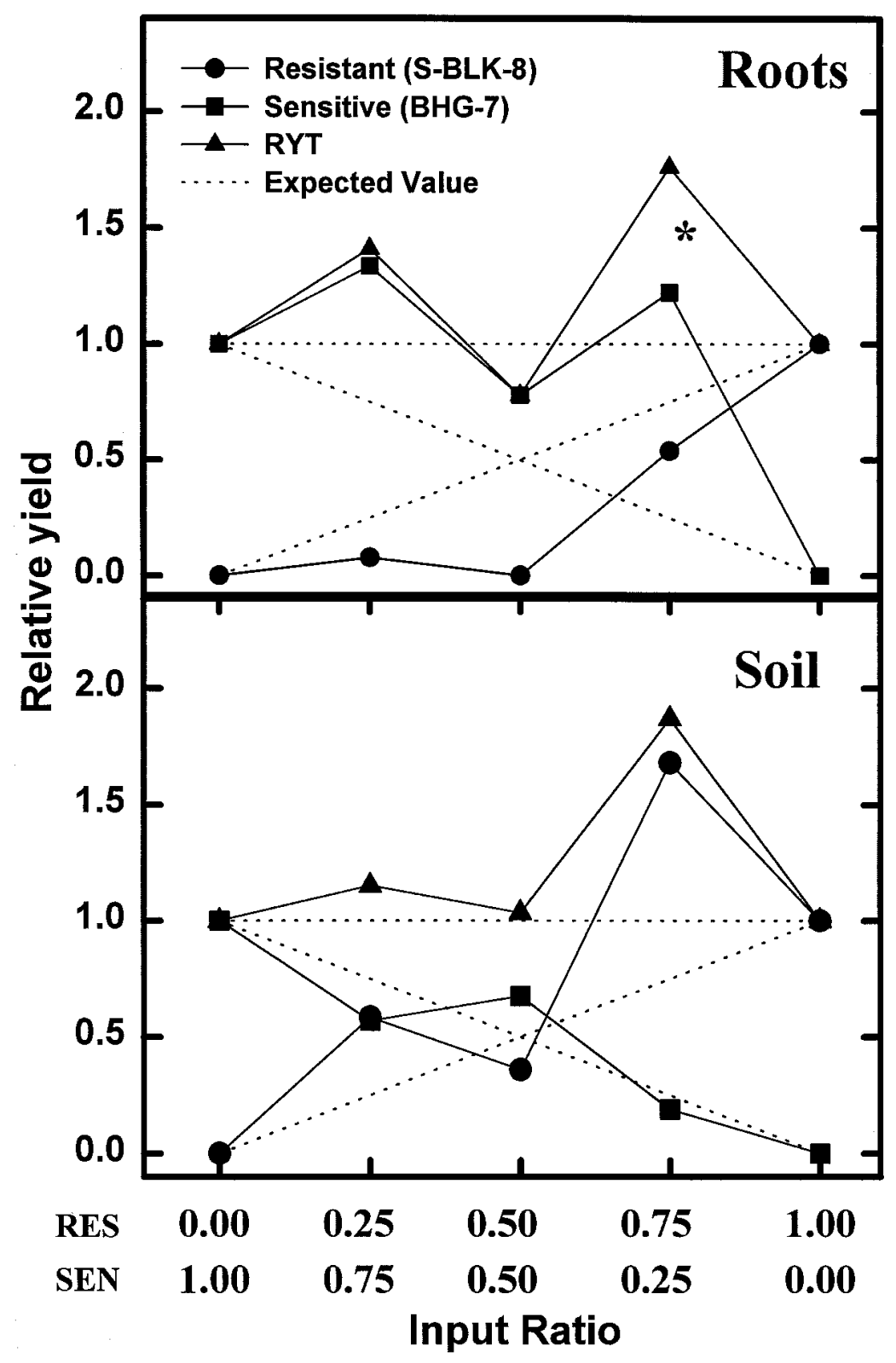

Fig. 3. Relative recoveries of a metalaxyl-resistant isolate (S-BLK-8) and a sensitive isolate (BHG-7) from sour orange roots and from soil 5 weeks after inoculation with different inoculum density ratios. RYT = relative total yield of both isolates. Expected values (dotted lines) are the reference values indicating equal inter- and intra-isolate competition. $*$ = significantly different from the reference values for each species according to the $t$ test, $P \leq 0.05$. Values of RYT were not significantly different from the reference value (1.0) according to a non-parametric sign test. 
cides resulted in a decrease in the quality of nursery stock in the state. Consequently, the use of systemic fungicides in nurseries is no longer recommended (14). If the use of methyl bromide and other soil fumigants is banned, then nurserymen will have to produce trees in pathogen-free, artificial potting mixes under good sanitary conditions to avoid Phytophthora problems.

Metalaxyl-resistant isolates of $P$. nicotianae grew as well, or in some cases better, on plates with $100 \mu \mathrm{g} / \mathrm{ml}$ of metalaxyl than they did on plates with no metalaxyl. In contrast, sensitive isolates produced virtually no growth on plates with 1.0 $\mu \mathrm{g} / \mathrm{ml}$ of metalaxyl. Thus, citrus isolates of $P$. nicotianae are as sensitive or more so than species from other crops. However, when metalaxyl resistance develops, citrus isolates are as tolerant or more so than isolates from other crops $(6,7,9,10)$. All resistant isolates from nurseries and from groves with trees from nurseries with resistance tolerated high levels of metalaxyl with no reduction of growth at $100 \mu \mathrm{g} / \mathrm{ml}$. Sensitive isolates from those locations were highly sensitive and usually produced no growth at $1.0 \mu \mathrm{g} / \mathrm{ml}$. However, many of the isolates collected at random from groves where the history of metalaxyl was unknown showed some level of tolerance for metalaxyl and were classified as insensitive. Thus, as with other species of Phytophthora $(3,9,17)$, metalaxyl resistance is probably attributable to a single gene which confers a high level of resistance. However, there may be many minor genes which affect the sensitivity to the fungicide at low levels.

In greenhouse tests, metalaxyl generally failed to control root rot caused by resistant isolates, but the fungicide occasionally reduced propagule densities significantly. Root rot caused by metalaxyl-resistant isolates was generally controlled by fosetyl-Al. However, fosetyl-Al was phyto- toxic, especially when applied as a soil drench at high concentrations. Thus, high levels of root rot were observed on those treatments even though propagule densities were low.

In replacement series tests in the greenhouse, the competitive ability of resistant strains varied with the isolate. In one test, a resistant isolate, S-BLK-8, was out-competed by a sensitive isolate, BLTN. However, in another pairing, S-BLK-8 competed well against a sensitive isolate, BHG-7. While the sensitive isolate, BLTN, competed well against one resistant isolate, S-BLK-8, it was less successful against resistant isolate D54S. Thus, it does not appear that resistant isolates are inherently less fit than sensitive isolates, and at least some can compete favorably with the sensitive isolates.

The fitness of resistant isolates is also borne out by the field study. Propagule densities of resistant isolates did not decline substantially over the 2.5-year study, even in the absence of metalaxyl usage. Metalaxyl application decreased propagule densities slightly even on trees with high levels of resistance, but there was an increase in propagule densities with time on treated trees. The percentage of resistant isolates was not significantly affected by treatment either positively or negatively. The increase in resistant isolates on trees which originally had no or low levels of resistance may be due to movement of propagules by rain water, since the increase occurred on both treated and untreated trees.

Excessive dependence on the use of metalaxyl in citrus nurseries has resulted in extensive development of resistant isolates of $P$. nicotianae. Those isolates have now been widely disseminated on nursery trees into Florida citrus groves, not only in new plantings but also as replants in existing groves. Results indicate the metalaxyl- resistant isolates can compete well with sensitive isolates and will persist for long periods even after metalaxyl use has been discontinued. Metalaxyl appears to be effective for disease control as long as the proportion of resistant isolates is low, but its use will have to be discontinued in groves where the percentage of resistant isolates is high.

\section{ACKNOWLEDGMENTS}

We thank Rachelle Childress, Carl Haun, Becky King, and Nancy Timmer for excellent technical assistance.

\section{LITERATURE CITED}

1. Adee, S. R., Pfender, W. F., and Harnet, D. C. 1990. Competition between Pyrenophora tritici-repentis and Septoria nodorum in the wheat leaf as measure with de Wit replacement series. Phytopathology 80:1177-1182.

2. Agostini, J. P., Timmer, L. W., Castle, W. S., and Mitchell, D. J. 1991. Effect of citrus rootstocks on soil populations of Phytophthora parasitica. Plant Dis. 75:296-300.

3. Bhat, R. G., McBlain, B. A., and Schmitthener, A. F. 1993. The inheritance of resistance to metalaxyl and to fluorophenylalanine in matings of homothallic Phytophthora sojae. Mycol. Res. 97:865-870.

4. Carter, G. A., Smith, R. M., and Brent, K. J. 1982. Sensitivity to metalaxyl of Phy tophthora infestans populations in potato crops in southwest England in 1980 and 1981 Ann. Appl. Biol. 100:433-441.

5. Coleman, B. 1993. Recent studies address fungicide resistance. Citrus Ind. 74(10):40-41

6. Csinos, A. S., and Bertrand, P. F. 1994. Distribution of Phytophthora parasitica var. nicotianae races and their sensitivity to metalaxyl in Georgia. Plant Dis. 78:471-474.

7. Ferrin, D. M., and Kabashima, J. N. 1991. In vitro insensitivity to metalaxyl of isolates of Phytophthora citricola and Phytophthora parasitica from ornamental hosts in southern California. Plant Dis. 75:1041-1044.

8. Fisher, J. 1993. CIBA-GEIGY addresses Phytophthora resistance to Ridomil. Citrus Ind. 74(6):28-29.

9. Goodwin, S. B., and McGrath, M. T. 1995. Insensitivity to metalaxyl among isolates of Phytophthora erythroseptica causing pink rot of potato in New York. Plant Dis. 79:967.

Table 6. The effect of metalaxyl treatment on the total population densities and the percentage of metalaxyl-resistant isolates on Sunburst tangerine trees on Cleopatra mandarin rootstock originally selected to have high, low, and no populations of metalaxyl-resistant isolates

\begin{tabular}{|c|c|c|c|c|c|c|c|c|c|c|c|c|}
\hline \multirow[b]{3}{*}{ Date } & \multicolumn{6}{|c|}{ Total propagules $/ \mathrm{cm}^{3}$} & \multicolumn{6}{|c|}{ Metalaxyl-resistant propagules ( $\%$ of total) } \\
\hline & \multicolumn{3}{|c|}{ Metalaxyl treated ${ }^{w}$} & \multicolumn{3}{|c|}{ Not treated } & \multicolumn{3}{|c|}{ Metalaxyl-treated $^{\mathrm{x}}$} & \multicolumn{3}{|c|}{ Not treated } \\
\hline & $\mathbf{H}^{\mathbf{y}}$ & $\mathbf{L}$ & O & $\mathbf{H}$ & $\mathbf{L}$ & O & $\mathbf{H}$ & $\mathbf{L}$ & O & $\mathbf{H}$ & $\mathbf{L}$ & O \\
\hline Nov 94 & 13 & 26 & 8 & 30 & 23 & 15 & 100 & 4 & 0 & 92 & 9 & 0 \\
\hline Apr 95 & 15 & 7 & 15 & 53 & 53 & 11 & 72 & 7 & 0 & 73 & 3 & 0 \\
\hline Jul 95 & 20 & 2 & 2 & 9 & 32 & 29 & 65 & 100 & 0 & 63 & 83 & 0 \\
\hline Oct 95 & 11 & 24 & 3 & 23 & 20 & 28 & 100 & 3 & 0 & 94 & 45 & 4 \\
\hline Apr 96 & 11 & 32 & 6 & 38 & 28 & 8 & 64 & 27 & 70 & 89 & 11 & 24 \\
\hline Jul 96 & 29 & 30 & 11 & 20 & 28 & 10 & 93 & 49 & 48 & 65 & 86 & 21 \\
\hline Oct 96 & 34 & 22 & 12 & 33 & 36 & 20 & 77 & 9 & 9 & 94 & 42 & 0 \\
\hline May 97 & 25 & 66 & 19 & 38 & 42 & 39 & 68 & 10 & 0 & 73 & 38 & 15 \\
\hline Aug 97 & 46 & 17 & 18 & 60 & 48 & 42 & 41 & 14 & 0 & 100 & 29 & 10 \\
\hline$\overline{\mathrm{X}}$ & 23 & 25 & 10 & 34 & 34 & 22 & 75 & 25 & 14 & 83 & 38 & 8 \\
\hline$R^{2 \mathrm{z}}$ & 0.09 & 0.1 & 0.1 & -0.01 & -0.01 & -0.004 & 0.001 & -0.02 & 0.03 & -0.01 & 0.001 & 0.01 \\
\hline$P^{\mathrm{z}}$ & 0.01 & 0.02 & 0.01 & 0.84 & 0.91 & 0.38 & 0.81 & 0.82 & 0.98 & 0.80 & 0.29 & 0.21 \\
\hline
\end{tabular}

${ }^{\mathrm{w}}$ Total propagule densities were significantly less than in the non-treated control $(P=0.01)$.

$\mathrm{x}$ There was no significant difference in the percentage of resistant isolates in the metalaxyl-treated and not treated, $(P=0.86)$.

y Total number of propagules and the percentage of the propagules resistant to metalaxyl in groups of 5 to 7 trees selected in November 1994 to have a high percentage of resistant propagules $(\mathrm{H})$, a low percentage $(\mathrm{L})$, or none $(\mathrm{O})$.

${ }^{\text {z }}$ Adjusted $R^{2}$ and corresponding $P$ values for the regression of propagule densities and percentages of resistant isolates over time. 
10. Goodwin, S. B., Sujkowski, L. S., and Fry, W. E. 1996. Widespread distribution and probable origins of resistance to metalaxyl in clonal genotypes of Phytophthora infestans in the United States and Western Canada. Phytopathology 86:793-800.

11. Graham, J. H. 1995. Root regeneration and tolerance of citrus rootstocks to root rot caused by Phytophthora nicotianae. Phytopathology 85:111-117.

12. Graham, J. H., and Timmer, L. W. 1992. Phytophthora diseases of citrus. Pages 250269 in: Plant Diseases of International Importance. Diseases of Fruit Crops. Vol. III. J. Kumar, H. S. Chaube, M. S. Singh, and A. N. Mukhpadhyay, eds. Prentice Hall, Englewood Cliffs, NJ.

13. Hall, G. 1993. An integrated approach to analysis of variation in Phytophthora nicotianae and a redescription of the species. Mycol. Res. 97:559-574.

14. Knapp, J. L., ed. 1997. Florida Citrus Pest Management Guide. Univ. Florida Inst. Food and Agric. Sci. Publ. No. SP-43.
15. Mitchell, D. J., Kannwischer-Mitchell, M. E., and Zentmyer, G. A. 1986. Isolating, identifying, and producing inoculum of Phytophthora spp. Pages 63-66 in: Methods for Evaluating Pesticides for Control of Plant Pathogens. K. D. Hickey, ed. American Phytopathological Society, St. Paul, MN.

16. Sandler, H. A., Timmer, L. W., Graham, J. H., and Zitko, S. E. 1989. Effect of fungicide applications on populations of Phytophthora parasitica and on feeder root densities and fruit yields of citrus trees. Plant Dis. 73:902906.

17. Shattock, R. C. 1988. Studies of the inheritance of resistance to metalaxyl in Phytophthora infestans. Plant Pathol. 34:4-11.

18. Steel, R. G. D., and Torrie, J. H. 1980. Principles and Procedures of Statistics, a Biometrical Approach. McGraw-Hill, Inc., New York.

19. Timmer, L. W., and Menge, J. A. 1988. Phytophthora-induced diseases. Pages 22-24 in: J. O. Whiteside, S. M. Garnsey, and L. W. Timmer, eds. Compendium of Citrus Diseases. American Phytopathological Society, St. Paul,
MN.

20. Timmer, L. W., Sandler, H. A., Graham, J. H., and Zitko, S. E. 1988. Sampling citrus orchards in Florida to estimate populations of Phytophthora parasitica. Phytopathology 78:940.

21. Timmer, L. W., Sandler, H. A., Graham, J. H., and Zitko, S. E. 1989. Phytophthora feeder root rot of bearing citrus: fungicide effects on soil populations of Phytophthora parasitica and citrus tree productivity. Proc. Fla. State Hortic. Soc. 102:5-7.

22. Tsao, P. H. 1971. Chlamydospore formation in sporangium-free liquid cultures of $P h y-$ tophthora parasitica. Phytopathology 61:1412-1413.

23. Zitko, S. E., and Timmer, L. W. 1994. Competitive parasitic abilities of Phytophthora parasitica and $P$. palmivora on fibrous roots of citrus. Phytopathology 84:1000-1004.

24. Zitko, S. E., Timmer, L. W., and Castle, W. S. 1987. Survey of Florida citrus nurseries for Phytophthora spp. Proc. Fla. State Hortic. Soc. 100:82-85. 